\title{
A new parameterization of the UV irradiance altitude dependence for clear-sky conditions and its application in the on-line UV tool over Northern Eurasia
}

\author{
Nataly Chubarova, Yekaterina Zhdanova, and Yelena Nezval \\ Faculty of Geography, Moscow State University, GSP-1, 119991, Moscow, Russia \\ Correspondence to: Nataly Chubarova (chubarova@geogr.msu.ru) \\ Received: 10 March 2016 - Published in Atmos. Chem. Phys. Discuss.: 3 May 2016 \\ Revised: 30 July 2016 - Accepted: 18 August 2016 - Published: 23 September 2016
}

\begin{abstract}
A new method for calculating the altitude UV dependence is proposed for different types of biologically active UV radiation (erythemally weighted, vitaminD-weighted and cataract-weighted types). We show that for the specified groups of parameters the altitude UV amplification $\left(A_{\mathrm{UV}}\right)$ can be presented as a composite of independent contributions of UV amplification from different factors within a wide range of their changes with mean uncertainty of $1 \%$ and standard deviation of $3 \%$ compared with the exact model simulations with the same input parameters. The parameterization takes into account for the altitude dependence of molecular number density, ozone content, aerosol and spatial surface albedo. We also provide generalized altitude dependencies of the parameters for evaluating the $A_{\mathrm{UV}}$. The resulting comparison of the altitude UV effects using the proposed method shows a good agreement with the accurate 8-stream DISORT model simulations with correlation coefficient $r>0.996$. A satisfactory agreement was also obtained with the experimental UV data in mountain regions. Using this parameterization we analyzed the role of different geophysical parameters in UV variations with altitude. The decrease in molecular number density, especially at high altitudes, and the increase in surface albedo play the most significant role in the UV growth. Typical aerosol and ozone altitude UV effects do not exceed 10-20\%. Using the proposed parameterization implemented in the on-line UV tool (http://momsu.ru/uv/) for Northern Eurasia over the PEEX domain we analyzed the altitude UV increase and its possible effects on human health considering different skin types and various open body fraction for January and April conditions in the Alpine region.
\end{abstract}

\section{Introduction}

Biologically active UV radiation (BAUVR) is an important environmental factor, which significantly affect human health and nature (Van der Leun et al., 1998; Bornman et al., 2011). Enhanced levels of UV radiation lead to different types of skin cancer (basal and squamous cell carcinomas, cutaneous melanoma), to various eye diseases (cataract, photokeratitis, squamous cell carcinoma, ocular melanoma, variety of corneal/conjunctival effects), and to immunosuppression. However, small doses of UV radiation have a positive effect on health through the vitamin D generation (Bornman et al., 2011).

UV radiation is affected by astronomical factors (solar zenith angle, solar-earth distance, solar activity), by different atmospheric characteristics (total ozone content, cloudiness, aerosol, optically effective gases), and by surface albedo (Madronich, 1993; Bais et al., 2007; Bekki et al., 2011). However, the altitude above sea level has also a significant influence on UV radiation (Bais et al., 2007). There are a lot of studies and special field campaigns in different geographical regions, which were devoted to the analysis of the altitude UV effect (Bernhard et al., 2008; Blumthaler and Ambach, 1988; Blumthaler et al., 1994, 1997; Dahlback et al., 2007; Lenoble et al., 2004; Piacentini et al., 2003; Pfeifer et al., 2006; Sola et al., 2008; etc.). The UV enhancement at high altitudes is detected not only due to smaller molecular scattering, but also due to usually observed decreasing in total ozone content and aerosol, and increasing in surface albedo, which in turn enhances 3-D reflection from slopes of mountains covered by snow (Lenoble et al., 2004). In addition, 
variation of cloud properties with altitude can also change the level of UV radiation.

The UV records in mountainous areas demonstrate extremely high levels. The highest UV values are observed in Andes in Bolivia (Pfeifer et al., 2006; Zaratti et al., 2003), where UV index ${ }^{1}$ can be sometimes close to 20 . Very high UV levels were also recorded at high-altitude deserts in Argentina (Piacentini et al., 2003). In Tibet the UV index frequently exceeded 15 on clear days and occasionally exceeded 20 on partially cloudy days (Dahlback et al., 2007). At the European alpine stations in summer conditions the UV indices are often higher than 11 (Hülsen, 2012). For example, high UV index up to 12 was observed in mountainous areas in Italy (Casale et al., 2015). A significant UV growth with the altitude was also obtained at different sites in Austria and Switzerland (Rieder et al., 2010). In winter, erythemally weighted UV irradiance is about $60 \%$ higher than that at lower-altitude European sites (Gröbner et al., 2010). In the Arctic the comparison of summer UV measurements at Summit (3202 m a.s.l.) and Barrow ( $\sim$ m a.s.l.) stations shows significant enhancing of about $30-40 \%$ in clear sky conditions at the elevated site (Bernhard et al., 2008).

The UV altitude gradients obtained from model calculations vary within the range of $3.5-6 \% \mathrm{~km}^{-1}$ in the cloudless atmosphere if all other parameters (ozone, aerosol, surface albedo) do not change with the altitude (Chubarova and Zhdanova, 2013). The smaller values of the estimated UV altitude gradients $\left(3.5 \% \mathrm{~km}^{-1}\right)$ were obtained in conditions with high surface albedo at both sea level and high altitude, since the larger diffuse component at sea level, to some extent, compensates the higher direct flux due to a smaller total optical depth at higher location. However, the experimental UV altitude gradients are often much higher due to the presence of additional altitude changes in the atmospheric parameters. According to different field campaigns UV altitude gradients vary within 5-11\% km ${ }^{-1}$ (Pfeifer et al., 2006; Zaratti et al., 2003; Schmucki and Philipona, 2002), 11-14\% $\mathrm{km}^{-1}$ according to (Sola et al., 2008), and in some cases can reach $31 \% \mathrm{~km}^{-1}$ (Pfeifer et al., 2006). The existence of spectral dependence in absorption coefficients of ozone as well as in molecular scattering cross sections provides a pronounced spectral character of the altitude UV effect, which was obtained in many publications (Blumthaler et al., 1994; Sola et al., 2008).

However, the continuous UV records in mountainous area are still very rare due to the complexity of accurate UV measurements in severe conditions. The accurate results of measurements from different field campaigns devoted to the evaluation of altitude UV effects shown in (Bernhard et al., 2008; Blumthaler and Ambach, 1988; Blumthaler et al., 1994, 1997; Dahlback et al., 2007; Lenoble et al., 2004; Pi-

\footnotetext{
${ }^{1} \mathrm{UV}$ index is a widely used characteristic, which is equal to erythemally weighted irradiance expressed in $\left(\mathrm{W} \mathrm{m}^{-2}\right)$ multiplied on 40 (Vanicek et al., 2000).
}

acentini et al., 2003; Pfeifer et al., 2006; Seckmeyer et al., 1997; Sola et al., 2008; Zaratti et al., 2003) provide precise, however, local character of this phenomenon, which results in various altitude UV gradients.

At the same time, the accurate RT (radiative transfer) model simulations (Liou, 2010) are very time consuming and can not be used in different on-line tools or other applications. There are also a lot of UV model assessments for the past and future UV climate scenarios but usually they are given with the coarse spatial resolution, which does not allow a user to obtain the accurate estimates over the particular mountainous location.

In addition, the limiting factor of the UV calculation accuracy is the uncertainty of input geophysical parameters, which significantly increases at high altitudes. Hence, another task was to obtain some generalized dependencies of the input parameters using the available data sources.

The objective of this paper is to provide the accurate parameterization for different types of biologically active radiation for the estimation of UV level at different altitudes taking into account the generalized altitude dependencies of different geophysical parameters. Using the proposed parameterization we will also discuss the consequence of the enhanced UV level at high altitudes for human health using the classification of UV resources via a specially developed online interactive UV tool.

\section{Materials and methods}

In order to account for different effects of UV radiation on human health we analyze three types of BAUVR: erythemally weighted, vitamin D-weighted, and cataract-weighted irradiances, which are calculated using the following equation:

$$
Q_{\text {bio }}=\int_{280}^{400} Q_{\lambda} F_{\lambda} \mathrm{d} \lambda,
$$

where $Q_{\lambda}$ is the spectral flux density, $F_{\lambda}$ is the respective biological action spectrum.

We used erythemal action spectrum according to Diffey et al. (1998), vitamin D spectrum - according to Bouillon et al. $(2006)^{2}$, and cataract-weighted spectrum according to Oriowo et al. (2001). Various types of BAUVR action spectrum have different efficiency within the UV range (Fig. 1). For their characterization we used the effective wavelengths, which are calculated as follows:

$\lambda_{\text {eff }}=\int Q_{\lambda} \lambda \mathrm{d} \lambda / \int Q_{\lambda} \mathrm{d} \lambda$

\footnotetext{
${ }^{2}$ Note, that a widely used conception of action spectra, which is based on the additivity of wavelength contribution, still has not be well documented for vitamin D action spectrum (Norval et al., 2010) and needs further studies.
} 


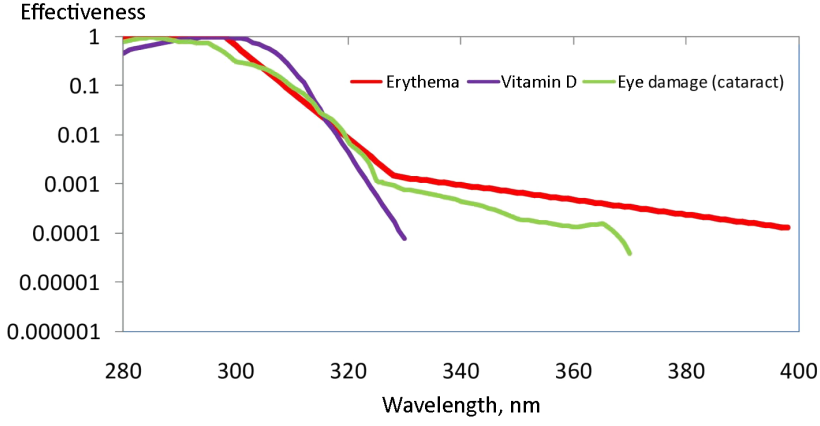

Figure 1. Action spectra for erythema (Diffey et al., 1998), vitamin D (Bouillon et al., 2006) and for eye damage (cataract) (Oriowo et al., 2001) effects.

According to our estimates, for example, at high solar elevation $\left(h=60^{\circ}\right)$ and for the variety of other parameters (total ozone, aerosol and surface albedo) the effective wavelength for erythemally weighted irradiance $\left(Q_{\text {ery }}\right)$ is $\sim 317 \mathrm{~nm}$, for cataract-weighted irradiance ( $Q_{\text {eye }}$ ) it is $\sim 313 \mathrm{~nm}$, and for vitamin D-weighted irradiance $\left(Q_{\text {vitD }}\right)$ it is $\sim 308 \mathrm{~nm}$. These changes in effective wavelengths for various BAUVR types indicate their different sensitivity to the ozone absorption, molecular scattering and aerosol attenuation, which vary dramatically within this spectral range, and, as a result, explain different BAUVR responses to the changes in these geophysical parameters.

All the simulations were fulfilled using one dimensional radiative TUV (Tropospheric Ultraviolet-Visible) model with 8 -stream DISORT RT method (Madronich and Flocke, 1997) and $1 \mathrm{~nm}$ spectral resolution. The uncertainty of the RT method is less than $1 \%$ (Liou, 2010). A good agreement between the experimental spectral data in different geographical regions and simulated results using this RT method if the input atmospheric parameters were known was also shown in Badosa et al. (2007).

Several experimental data sets were used. For obtaining the generalized altitude dependence of aerosol optical depth (AOD) we used the data of sun/sky CIMEL photometers from different AERONET sites located at different heights above sea level (Holben et al., 1998). These data account for the near-ground emission sources of the aerosol at various altitudes in the aerosol column content. The estimated uncertainty for aerosol optical depth in UV spectral region is about 0.02 . The uncertainty for single scattering albedo is about 0.03 at $\mathrm{AOD}_{440}>0.4$ and the uncertainty for all other inversion parameters is not higher than $10 \%$ (Holben et al., 2006).

In addition, the data set of historical Moscow State University complex field campaigns over mountainous areas at Pamir $\left(38-40.5^{\circ} \mathrm{N}, 73-74^{\circ} \mathrm{E}, H=1.0-3.9 \mathrm{~km}\right)$, and Tyan Shan $\left(43^{\circ} \mathrm{N}, 77^{\circ} \mathrm{E}, H=3.47 \mathrm{~km}\right)$ was applied in the analysis (Belinsky et al., 1968). It includes the data records of total ozone content and aerosol optical depth at $330 \mathrm{~nm}$, which had been measured with the help of M-83 filter ozonometer, and UV irradiance less than $320 \mathrm{~nm}$ - by the UVM-5 instrument calibrated against the spectroradiometer BSQM (the Boyko's Solar Quartz Monochromator) described in Belinsky et al. (1968). The description of the BSQM and the details of the calibration were also discussed in Chubarova and Nezval' (2000). The uncertainties of UV measurements less $320 \mathrm{~nm}$ due to the calibration procedure were considered to be about $10 \%$ (Belinsky et al., 1968). However, to avoid the calibration errors only relative measurements were used in this study. The residual uncertainty due to possible existence of slight variation in spectral response of the instrument and their temperature dependence was estimated to be about 5-7\%. The obscurity of the horizon at all sites was less than $10^{\circ}$. The field campaigns were carried out during summer periods, when no snow was detected at the surface. The snow covered mountainous peaks were only observed at Tyan Shan at relatively large distance of more than $30 \mathrm{~km}$ from the site.

We also used the LIVAS database (Lidar Climatology of Vertical Aerosol Structure for Space-Based Lidar Simulation Studies, http://lidar.space.noa.gr:8080/livas/). This is a 3-dimensional global aerosol climatology based on satellite lidar CALIPSO observations at 532 and $1064 \mathrm{~nm}$, EARLINET ground-based measurements and a combination of input data from AERONET, aerosol models, etc. The final LIVAS climatology includes 4-year (2008-2011) timeaveraged $1 \times 1^{\circ}$ global fields (Amiridis et al., 2015). We used the annual aerosol extinction profiles at $355 \mathrm{~nm}$ for calculating aerosol optical depth over various points at different altitudes in the Alpine and the Caucasian mountainous regions in Europe and over the high-elevated regions in Asia. It should be mentioned that the LIVAS averages all Calipso overpasses over a $1 \times 1^{\circ}$ cell and characterizes only the mean altitude within the cell. This provides some additional uncertainties in its aerosol extinction altitude dependence evaluation. On average, according to Amiridis et al. (2015) the absolute difference in LIVAS AOD is within 0.1 agreement with AERONET AOD values in UV and visible region of spectrum.

In addition, we estimated UV resources at different altitudes according to the approach given in Chubarova and $\mathrm{Zh}-$ danova (2013), which has been developed on the base of international classification of UV index (Vanicek et al., 2000) and the vitamin $\mathrm{D}$ threshold following the recommendations given in Bouillon et al. (2006). In Bouillon et al. (2006) there were simple recommendations of choosing the minimum vitamin D dose (MVitDD) threshold using one fifth Minimal Erythemal Dose (MED) for a one fifth body area. In this study according to the new guidelines a healthy level of vitamin D3 was increased from $400 \mathrm{IU}$ recommended in Bouillon et al. (2006) to $1000 \mathrm{IU}$ in McKenzie et al. (2014). The possibility to account for the open body fraction as a function of the effective air temperature was also applied in the UV resources estimating method (Chubarova and Zhdanova, 
2013) as it had been proposed in (McKenzie et al., 2009). According to this approach we defined noon UV deficiency when UV dose is smaller than the vitamin D threshold during 11:30-12:30 solar time noon period, and $100 \% \mathrm{UV}$ deficiency category, when it is not possible to receive vitamin $\mathrm{D}$ throughout the whole day. The $U V$ optimum category is determined when the UV dose does not exceed erythemal threshold but it is possible to receive UV dose, necessary for vitamin $\mathrm{D}$ at noon hour. Several subclasses of $U V$ excess are attributed to the thresholds depending on the standard UV index categories: moderate UV excess class, which relates to moderate category of hourly UV index, high UV excess, very high UV excess, and extremely high UV excess category. Further details about this approach can be found in Chubarova and Zhdanova (2013). Currently, in the assessment of UV resources we do not take into account for the eye damage UV effects, since there is no reliable regulation on the UV threshold for this type of BAUVR.

\section{Results}

\subsection{The general description of the approach}

It is widely known that "the solution of the radiative transfer equation is possible to derive by numerous solution methods and techniques" (Liou, 2010). However, the accurate RT methods usually require a lot of computer time and can not be used in several applications. The simulated intensity and UV flux density (or irradiance) has a complicated non-linear dependence on many geophysical parameters, however, our numerous simulations of UV irradiance using the accurate 8 -stream discrete ordinate RT method show that within a variety of geophysical parameters one can obtain the parameterized altitude correction by taking into account for the quasi-independent terms driven by different geophysical factors. Some of them are independent due to different vertical profiles (for example, ozone maximum in the stratosphere compared with aerosol and molecular maximum in the troposphere). Some of them are dependent (for example, surface albedo UV effects depend on molecular and aerosol loading), but, as we show later, this factor can be also considered as a one joint term.

Using this assumption, we propose a parameterization, where biologically active UV irradiance at the altitude $H\left(Q_{\text {bio }}(H)\right)$ can be estimated from $Q_{\text {bio }}$ at zero altitude ( $H=0 \mathrm{~km}$ a.s.l.) with an independent account for the terms, which are affected by different geophysical factors:

$$
\begin{aligned}
& Q_{\text {bio }}\left(M_{H}, X_{H}, \mathrm{AOD}_{H}, S_{H}\right)=Q_{\text {bio }}\left(M_{0}, X_{0}, \mathrm{AOD}_{0}, S_{0}\right) \\
& \cdot A_{M} A_{X} A_{\mathrm{AOD}} A_{S(M, \mathrm{AOD}, \text { cloud })},
\end{aligned}
$$

where $A_{M}, A_{X}, A_{\mathrm{AOD}}$ are the UV amplifications, respectively, due to the altitude decrease in molecular number density $(M)$, ozone $(X)$, and aerosol optical depth (AOD). $A_{S(M, \mathrm{AOD}, \text { cloud })}$ is the UV amplification due to the increase in surface albedo $S$, which is typically observed with the altitude. This characteristic is also a function of a change in molecular number density, aerosol and cloud characteristics with height due to the processes of multiple scattering. Further, only the effects in the cloudless atmosphere are considered. The total UV amplification $\left(A_{\mathrm{uv}}\right)$ with altitude $H$ can be rewritten from Eq. (3) as

$$
\begin{aligned}
A_{\mathrm{UV}} & =A_{M} A_{X} A_{\mathrm{AOD}} A_{S} \\
& =\frac{Q_{\text {bio }}\left(M_{H}, X_{H}, \mathrm{AOD}_{H}, S_{H}\right)}{Q_{\text {bio }}\left(M_{0}, X_{0}, \mathrm{AOD}_{0}, S_{0}\right)} .
\end{aligned}
$$

Let us consider separately the effects of different factors on UV irradiance at high altitudes. We specify them by using the accurate RT model simulations, different empirical data sets or by applying the important characteristics from different publications.

The possibility of this approach was tested directly by the accurate modelling for a variety of conditions at different solar elevations. The model simulations were made for the altitude changes from 0 to $5 \mathrm{~km}$ with the variations of aerosol optical depth at $340 \mathrm{~nm}$ within $\mathrm{AOD}_{340} \sim 0.0-0.4$, variations in total ozone from 350 to $250 \mathrm{DU}$, and surface albedo changes from zero to $S=0.9$ at different altitudes. As the input aerosol parameters, within UV spectral region we also used single scattering albedo SSA varying from 0.88 to 0.96 , factor of asymmetry $g=0.72$, and Angstrom exponent $\alpha$ varying from 0.6 to 1.5 , which are close to the aerosol background characteristics in Europe (Chubarova, 2009; Arola et al., 2009). We compared the $A_{\text {UV }}$ values calculated as a multiplication composite of different separate parameters $\left(A_{M}, A_{X}, A_{\mathrm{AOD}}\right.$, and $\left.A_{S}\right)$ according to Eq. (4) with the $A_{\mathrm{UV}}$ values, which were estimated as a ratio of direct simulations of BAUVR at the altitude $H=5 \mathrm{~km}$ and at zero ground level. The results of the comparisons are shown in Fig. 2. One can see a good agreement between the $A_{\mathrm{UV}}$ values obtained using multiplication of $A_{M} A_{X} A_{\mathrm{AOD}} A_{S}$ and the $A_{\mathrm{UV}}$ values from direct estimations of BAUVR. The correlation for all BAUVR types is higher than 0.99 with the mean relative difference of $-1 \pm 3 \%$ compared with the exact model simulations if the same input parameters are used. Hence, the proposed approach based on the independent account for the terms, which are affected by different geophysical factors can be applied with high accuracy.

\subsection{Molecular UV amplification with the altitude}

A decrease of atmospheric pressure, or molecular number density, with the height is a well-known factor of UV amplification. According to the 8-stream DISORT model simulations we found that the BAUVR dependence with the altitude has a linear change in the molecular atmosphere, which is clearly seen in Fig. 3. Hence, for its characterization we can apply a simple gradient approach. 
Table 1. Relative molecular gradients $G_{\mathrm{bio}_{M(A=0)}}\left(\% \mathrm{~km}^{-1}\right)$ at different solar elevations and ozone content for different types of BAUVR. Accurate model simulations. Surface albedo $=0$. Determination coefficient $R^{2}$ is higher than 0.997 in all cases. The standard error of $G_{\text {bio }_{M(A=0)}}$ is given in the brackets at $P=95 \%$.

\begin{tabular}{|c|c|c|c|c|c|c|}
\hline \multirow[t]{2}{*}{$\begin{array}{r}\text { h, solar } \\
\text { elevation, } \\
\text { degrees }\end{array}$} & $\begin{array}{r}\text { erythemally- } \\
\text { weighted } \\
\text { irradiance }\end{array}$ & $\begin{array}{l}\text { cataract- } \\
\text { weighted } \\
\text { irradiance }\end{array}$ & $\begin{array}{r}\text { vitamin } \\
\text { D-weighted } \\
\text { irradiance }\end{array}$ & $\begin{array}{r}\text { erythemally- } \\
\text { weighted } \\
\text { irradiance }\end{array}$ & $\begin{array}{l}\text { cataract- } \\
\text { weighted } \\
\text { irradiance }\end{array}$ & $\begin{array}{r}\text { vitamin } \\
\text { D-weighted } \\
\text { irradiance }\end{array}$ \\
\hline & \multicolumn{3}{|c|}{$X=300 \mathrm{DU}$} & \multicolumn{3}{|c|}{$X=500 \mathrm{DU}$} \\
\hline 10 & $4.5(0.04)$ & $3.8(0.04)$ & $1.8(0.01)$ & $4.8(0.05)$ & $3.9(0.04)$ & $0.8(0.03)$ \\
\hline 20 & $6.4(0.04)$ & $6.9(0.05)$ & $7.1(0.06)$ & $6.0(0.03)$ & $6.6(0.04)$ & $6.8(0.05)$ \\
\hline 30 & $6.7(0.01)$ & $7.2(0.02)$ & $7.8(0.02)$ & $6.1(0.01)$ & $7.0(0.01)$ & $7.8(0.02)$ \\
\hline 40 & $6.4(0.02)$ & $6.8(0.01)$ & $7.3(0.01)$ & $5.8(0.02)$ & $6.6(0.02)$ & $7.4(0.01)$ \\
\hline 50 & $6.0(0.03)$ & $6.2(0.03)$ & $6.7(0.03)$ & $5.5(0.03)$ & $6.1(0.03)$ & $6.8(0.03)$ \\
\hline 60 & $5.7(0.04)$ & $5.8(0.04)$ & $6.2(0.04)$ & $5.3(0.04)$ & $5.7(0.04)$ & $6.4(0.04)$ \\
\hline
\end{tabular}

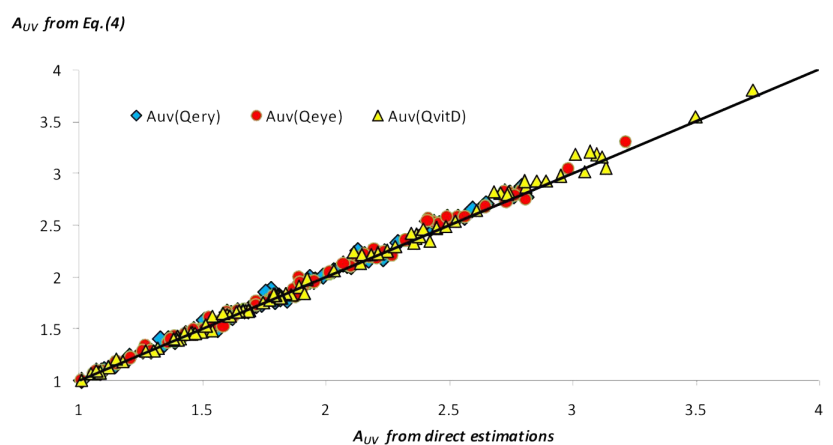

Figure 2. The comparison of $A_{\mathrm{UV}}$ amplification factor calculated from Eq. (4) as multiplication of $A_{M} A_{X} A_{\mathrm{AOD}} A_{S}$ with the direct model simulation of UV amplification. All the parameters $\left(A_{\mathrm{UV}}\right.$, $\left.A_{M} A_{X} A_{\mathrm{AOD}} A_{S}\right)$ were obtained from accurate model simulations. Comment. The simulations were performed for different altitudes $(H=0$ and $H=5 \mathrm{~km})$, aerosol optical depth $\left(\mathrm{AOD}_{340}=0\right.$, $0.2,0.4)$, single scattering albedo (SSA $=0.88,0.96)$, Angstrom exponent $(\alpha=0.6,1.0,1.5)$, total ozone $(X=250,300,350 \mathrm{DU})$, surface albedo $(S=0, S=0.9)$ and solar elevation $\left(h=20\right.$ and $\left.50^{\circ}\right)$. For estimating the UV amplification we assume at $H=0 \mathrm{~km}$ the conditions with $350 \mathrm{DU}, \mathrm{AOD}_{340}=0.4, S=0 \%$ and normalized the BAUVR at the altitude $H=5 \mathrm{~km}$ to the value calculated with these parameters.

For evaluating the UV amplification due to molecular effects the following expression is used:

$$
\begin{aligned}
A_{M} & =\frac{Q_{\text {bio }}\left(M_{H}, X_{0}, \mathrm{AOD}_{0}, S_{0}\right)}{Q_{\text {bio }}\left(M_{0}, X_{0}, \mathrm{AOD}_{0}, S_{0}\right)} \\
& =1+0.01 G_{\text {bio }, M}(S=0) \Delta H,
\end{aligned}
$$

where $G_{\mathrm{bio}, M}$ is the relative molecular gradient, in $\% \mathrm{~km}^{-1}$, $\Delta H$ is the difference in the altitudes, in kilometers. Note, that all other parameters do not change with the height.

The estimated relative molecular gradients for different types of BAUVR for various conditions are shown in Table 1 . At solar elevation $h=10^{\circ}$ there is a decrease in the

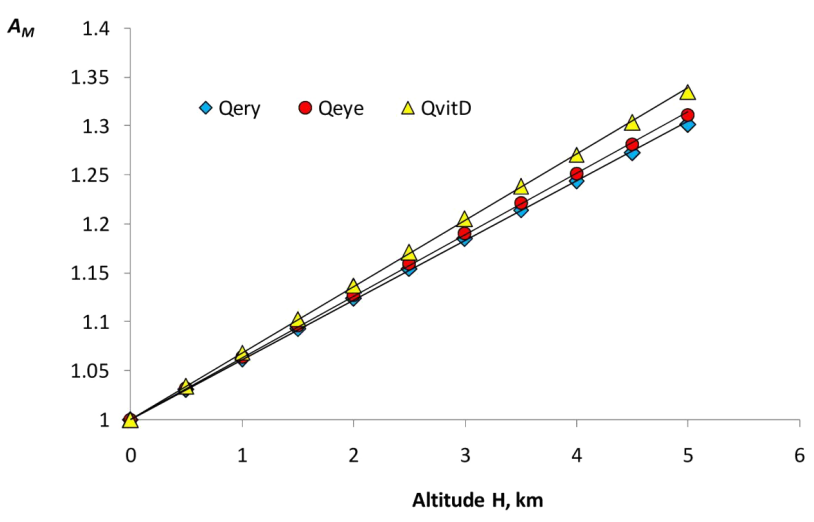

Figure 3. UV amplification due to decrease in molecular number density with the altitude $H$ according to accurate model simulations: TUV, 8-stream DISORT TUV model. $h=50^{\circ} . X=300 \mathrm{DU}$.

$G_{\mathrm{bio}, M}$ for different BAUVR and, especially, for vitamin$\mathrm{D}$ irradiance due to its smaller effective wavelength and the effects of stronger ozone absorption, which is increased at higher ozone content ( $X=500 \mathrm{DU})$. However, for solar elevation higher than $20^{\circ}$ the sensitivity of the $G_{\mathrm{bio}, M}$ values is around $6-7 \% \mathrm{~km}^{-1}$ and does not significantly change with variations in $h$ and $X$.

As an example, at the altitude of $5 \mathrm{~km}$ and at high solar elevation the molecular UV amplification according to Eq. (5) lies within $\sim 1.26-1.38$ depending on the type of BAUVR (see Table 1), which is in accordance with the accurate model simulations. However, at $h=10^{\circ}$ the UV amplification for erythemally weighted and cataract-weighted irradiances is about 1.18-1.23, while for vitamin D-weighted irradiance $A_{M}$ is only 1.04-1.09 depending on ozone content. The maximum UV amplification at the highest peak (Mt Everest, $H=8.848 \mathrm{~km}$ ) due to changes only in molecular scattering reaches 1.53-1.68 at high solar elevation depending on the type of BAUVR. 


\subsection{Ozone UV amplification with the altitude}

In order to account for the ozone decrease with the altitude we apply the existing linear dependence between UV radiation and total ozone $X$ in log-log scale. This approach was used in the definition of the radiation amplification factor (RAF) by Booth and Madronich (1994). As a result, the following equation can be written:

$\log \left(Q_{\text {bio }}\right)=\operatorname{RAF}\left(Q_{\text {bio }, h}\right) \log \left(X_{i}\right)+C$,

where $h$ is the solar elevation, $C$ is the constant.

The RAF values vary for different types of BAUVR. For example, at high solar elevation Radiation Amplification Factor for erythemally weighted irradiance $\mathrm{RAF}_{Q_{\text {ery }}}=1.2$, for vitamin D-weighted irradiance $-\mathrm{RAF}_{Q_{\text {vitD }}}=1.4$, for cataract-weighted irradiance $-\mathrm{RAF}_{Q_{\text {eye }}}=1.1$ (Bornman et al., 2011). However, we should take into account the RAF dependence on solar elevation $h$ due to the relative changes in solar spectrum with $h$. Using the results of accurate RT modelling and polynomial regression approach we have obtained RAF dependencies on solar elevation in degree over $h=10-90^{\circ}$ range for different types of BAUVR:

$$
\begin{aligned}
& \mathrm{RAF}_{Q_{\text {ery }}}(h)=-1.10 \times 10^{-4} \pm 1.49 \times 10^{-5} h^{2} \\
& \quad+1.57 \times 10^{-2} \pm 1.53 \times 10^{-3} h+0.665 \pm 0.0333 \\
& R^{2}=0.98 \\
& \mathrm{RAF}_{Q_{\text {vitD }}}(h)=1.66 \times 10^{-4} \pm 1.0 \times 10^{-5} h^{2} \\
& \quad-2.77 \times 10^{-2} \pm 1.1 \times 10^{-3} h+2.5121 \pm 0.0233 \\
& R^{2}=0.997 \\
& \mathrm{RAF}_{Q_{\text {eye }}}(h)=1.43 \times 10^{-6} \pm 1.0 \times 10^{-6} h^{3} \\
& \quad-2.02 \times 10^{-4} \pm 6.6 \times 10^{-5} h^{2}+4.83 \times 10^{-3} \\
& \quad \pm 2.9 \times 10^{-3} h+1.297 \pm 0.035 \\
& R^{2}=0.98
\end{aligned}
$$

where $R^{2}$ - is the determination coefficient. The standard error estimates of the coefficients in the equations are given at $P=95 \%$.

Note that a similar approach for accounting the RAF solar angle dependence was proposed in Herman (2010) with higher power degree.

As a result, the BAUVR at the altitude $H\left(Q_{\text {bio } H}\right)$ with the correction on ozone content can be written as follows:

$Q_{\text {bio } H}=Q_{\text {bio } 0}\left(X_{0} / X_{H}\right)^{\operatorname{RAF}\left(Q_{\text {bio }}, h\right)}$.

From Eq. (10) we can obtain the altitude UV amplification due to ozone using the altitude ozone gradient $G_{X}$

$$
\begin{aligned}
& \left(\mathrm{DU} \mathrm{km}^{-1}\right): \\
& \begin{aligned}
A_{X} & =\frac{Q_{\text {bio }}\left(M_{0}, X_{H}, \mathrm{AOD}_{0}, A_{0}\right)}{Q_{\text {bio }}\left(M_{0}, X_{0}, \mathrm{AOD}_{0}, A_{0}\right)} \\
& =\left(\frac{X_{0}}{X_{0}-G_{X} \cdot \Delta H}\right)^{\operatorname{RAF}\left(Q_{\text {bio }}, h\right)}
\end{aligned}
\end{aligned}
$$

We propose to apply the typical ozone altitude gradient $G_{X}$, which absolute value is about $3.5 \mathrm{DU} \mathrm{km}^{-1}$ according to monthly averaged ozone soundings measurements in Germany and observations in Bolivia (Reuder and Koepke, 2005; Pfeifer et al., 2006).

As an example, if we take into account only for this typical ozone decrease with the altitude, the UV enhancement at $5 \mathrm{~km}$ will be about $A_{X} \sim 1.06-1.11$ while at the highest peak (Mt. Everest, $H=8848 \mathrm{~m}$ ) $A_{X}$ will reach 1.11-1.22 at high solar elevations depending on the BAUVR type and initial ozone content at zero altitude within $X=250-350$ DU.

\subsection{Aerosol UV amplification with the altitude}

Aerosols can significantly change their characteristics with the altitude, affecting the level of BAUVR. Due to variations in size distribution and optical properties aerosol may have different radiative properties (aerosol optical depth, single scattering albedo, and phase function). One of the most important aerosol characteristics affecting UV radiation is aerosol optical depth.

For accounting the aerosol effect on UV attenuation we propose to apply the equation given in Chubarova (2009):

$Q_{\text {bio }}\left(\mathrm{AOD}_{340}\right)=Q_{\text {bio }(\mathrm{AOD}=0)}^{*}\left(1+\mathrm{AOD}_{340} B\right)$,

where $B=(0.42 m+0.93) \mathrm{SSA}-(0.49 m+0.97), Q_{\mathrm{bio}}^{*}$ is the BAUVR in aerosol free conditions, $m$ is the air mass, SSA is the single scattering albedo.

The Eq. (12) was obtained from the accurate model simulations for the conditions with low surface albedo $(S=$ 0.02 ), which is typical for grass. (Here and further we consider AOD at wavelength $340 \mathrm{~nm}\left(\mathrm{AOD}_{340}\right)$, since this wavelength corresponds to the standard UV channel in CIMEL sun/sky photometer, which is used in AERONET). The coefficients were obtained according to model simulations for $0<\mathrm{AOD}_{340}<0.8$, single scattering albedo $(0.8<\mathrm{SSA}<1)$, airmass $m \sim \sinh ^{-1}(m \leq 2)$, and Angstrom exponent $\alpha \sim 1$ $(0.6<\alpha<1.5)$. Note, that these are typical changes in main aerosol properties for European conditions in UV-A spectral range (Chubarova, 2009). However, the Angstrom exponent in UV-B spectral region can differ from this range and be even negative in particular conditions depending on aerosol size distribution and optical properties (Bais et al., 2007). Single scattering albedo in UVB spectral range according to the results of different field campaigns (Bornman et al., 2015) may vary from 0.7 to 0.97 with low SSA in the presence of black and brown carbon aerosol. Some results demonstrate no existence of SSA spectral dependence in UV (Barnard 
et al., 2008; Arola et al., 2009) but some results shows its spectral character (Bornman et al., 2015). We should also note that direct evaluation of SSA in UV-B spectral region is difficult because UV attenuation due to aerosol can occur together with the absorption in this spectral region by different gases (ozone, sulphur dioxide, formaldehyde, nitrogen dioxide, etc.). As a result we used the aerosol properties at $340 \mathrm{~nm}$ as input parameters for the BAUVR simulations since we consider typical aerosol conditions without forest fires and heavy industrial smoke. Radiative effects of the existing AOD spectral dependence are relatively small within the UV-B spectral range therefore we consider the same coefficients for different types of BAUVR.

Assuming that single scattering albedo and factor of asymmetry do not change with the altitude, we evaluated the UV amplification with the altitude due to aerosol optical depth. Using Eq. (12) the equation for $A_{\mathrm{AOD}_{340}}$ can be written as follows:

$$
\begin{aligned}
A_{\mathrm{AOD}_{340}} & =\frac{Q_{\text {bio }}\left(M_{0}, X_{0}, \mathrm{AOD}_{H}, A_{0}\right)}{Q_{\text {bio }}\left(M_{0}, X_{0}, \mathrm{AOD}_{0}, A_{0}\right)} \\
& =\frac{1+\mathrm{AOD}_{340, H} B}{1+\mathrm{AOD}_{340,0} B} .
\end{aligned}
$$

In some conditions single scattering albedo and asymmetry factor for visible wavelengths may have the altitude dependence (see, for example, the results of aircraft measurements in Western Siberia; Panchenko et al., 2012). However, there is no information on the altitude dependence of aerosol properties in UV spectral region from the in situ measurements over the PEEX area. Note, that the uncertainty of neglecting the altitude changes in single scattering albedo significantly decreases at small AOD observed at high altitudes and only the altitude changes in aerosol optical depth are usually taken into account in the standard tropospheric aerosol models (WMO, WCRP, 1987).

The aerosol optical depth at the altitude $H\left(\mathrm{AOD}_{340, H}\right)$ can be evaluated using the following expression:

$\mathrm{AOD}_{340, H}=\mathrm{AOD}_{340,0} f_{\mathrm{AOD}}(H)$,

where $f_{\mathrm{AOD}}(H)$ is the altitude dependence of aerosol optical depth.

There are a lot of model aerosol profiles for the free atmosphere conditions (see, for example, widely used aerosol models in WMO WCRP, 1987). However, these profiles can not be applied for high-elevated locations, which are usually characterized by a significant emission of primary aerosols or their precursors from nearby surface even in background conditions. To account for this kind of altitude AOD dependence we used different ground-based and satellite measurements described in the Sect. 2. Since our objective was to obtain the generalized aerosol altitude dependencies we used the monthly mean AOD data from different archives over different geographical regions in Eurasia. The dependence of aerosol optical depth as a function of altitude is shown in

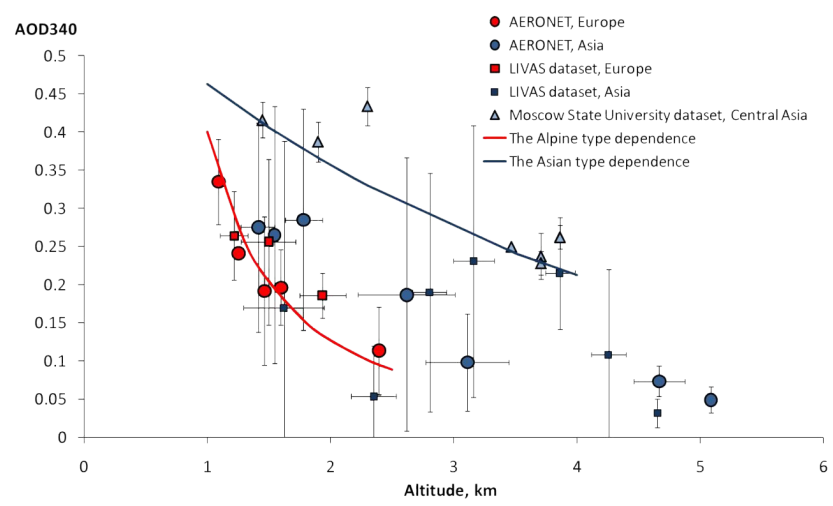

Figure 4. The altitude dependence of aerosol optical depth at $340 \mathrm{~nm}$ with $1 \sigma$ error bar according to the AERONET, LIVAS and the Moscow State University data sets over European and Asian regions. May-September period. The AOD at $330 \mathrm{~nm}$ the Moscow State University data set and the AOD at $355 \mathrm{~nm}$ from the LIVAS data sets were recalculated to AOD at $\lambda=340 \mathrm{~nm}$ using the Angstrom exponent $\alpha=1.0$. See further details in the text.

Fig. 4. Highly variable $\mathrm{AOD}_{340}$ values at different altitudes may be roughly combined in two groups, which are characterized by different rates of aerosol altitude decrease. Hence, in our parameterization we propose to distinguish these two types of the altitude aerosol dependence. The first one is characterized by a very strong aerosol optical depth decrease with the altitude. It was obtained mostly from the data of European AERONET sites in the Alpine zone as well as from several Asian sites in the sharp-peak mountainous areas. This dependence was also confirmed by the LIVAS data set measurements over the same areas.

The second one is characterized by a much more gradual altitude $\mathrm{AOD}_{340}$ decrease observed over flat elevated Asian regions according to the AERONET and LIVAS data set and the data obtained during Moscow State University field campaigns at the high-altitude plateau at Pamir and Tyan Shan mountainous regions in Central Asia. The main reason of such a character is the existence of the additional aerosol emission sources (i.e. loess, mineral aerosol) from the vast areas of deserts and semi-deserts elevated over sea level of up to $3-4 \mathrm{~km}$.

The first, Alpine-like type, can be parameterized as

$f_{\mathrm{AOD}}(H)=H^{-1.65}, R^{2}=0.4$.

The Alpine type aerosol altitude dependence was firstly obtained for the simulation of the UV climatology over Europe (Lityńska et al., 2012). However, the coefficients have been re-affirmed according to the monthly mean AOD over 19992012 period (case number $N=137$ ).

The second, so-called Asian type, can be obtained using the equation according to the Moscow State University expedition data set in Asian region. It is characterized by much 
flat dependence with the altitude:

$$
f_{\mathrm{AOD}}(H)=\exp (-0.26 H), R^{2}=0.8
$$

The proposed dependencies can be considered as the two classes with different altitude aerosol decreasing rates.

Both dependencies are accounted for the altitudes higher than $1 \mathrm{~km}$, since our analysis of AERONET data set has revealed the absence of the aerosol altitude dependence at the heights below $1 \mathrm{~km}$ due to prevailing the effects of different aerosol sources or their precursors there. However, over the particular location the altitude AOD dependence within the first kilometer can be found, of course.

We should note that the proposed altitude AOD dependencies according to Eqs. (15) and (16) are considered only as a first proxy for the most sharp and flat altitude dependencies. For a particular location and specific geographical conditions the AOD altitude dependence can be different. However, a user may easily substitute them in the proposed parameterization.

Although the AOD altitude dependence is pronounced, its influence on UV amplification highly depends on initial aerosol conditions at $H=0 \mathrm{~km}$, the type of the altitude profile, and solar elevation (see Eq. 12). For example, for the Alpine type aerosol altitude profile the UV amplification at $H=5 \mathrm{~km}$ is about $A_{\mathrm{AOD}}=1.05-1.10$ and does not exceed 1.11 at $H=8.848 \mathrm{~km}$ for typical aerosol at $H=$ $0 \mathrm{~km}\left(\mathrm{AOD}_{340}=0.36\right)$. However, for the polluted conditions characterized by $\mathrm{AOD}_{340}=0.8$ at $H=0 \mathrm{~km}$, the altitude UV amplification at $H=5 \mathrm{~km}$ is about $A_{\mathrm{AOD}} \sim 1.12$ 1.27 depending mainly on solar elevation. Note, that at $H=$ $8.848 \mathrm{~km}$ the effect is almost the same $\left(A_{\mathrm{AOD}} \sim 1.16-1.29\right)$. This will be further discussed below.

\subsection{UV amplification due to changes in surface albedo with the altitude}

The increase in surface albedo is one of the important factors, which is necessary to account for the effective calculations of BAUVR at high altitudes. Due to significant negative temperature gradients, the snow with high surface albedo can be observed even in summer conditions at high altitudes instead of vegetation with low UV albedo of about $S=0.02$ 0.05 (Feister and Grewe, 1995). Figure 5 demonstrates the enhancement in erythemally weighted irradiance due to the increase in surface albedo according to different experimental studies and the results of one-dimensional model simulations. One can see the UV increase of around $20 \%$ at the effective surface albedo close to $S=0.5$ (Simic et al., 2011; Huber et al., 2004; Smolskaia et al., 2003). On the average, there is an agreement between the calculation of UV amplification by 1-D model and the measurements at different mountainous regions up to effective surface albedo of $S \sim 0.5$. However, the accurate comparison of UV measurements with 3-D model (Diemóz and Mayer, 2007) shows the additional snow effect of about $\pm 1 \mathrm{UV}$ index value due to

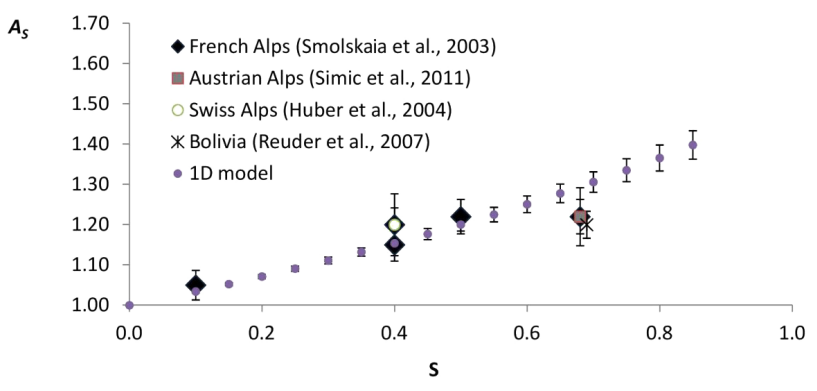

Figure 5. UV amplification due to the surface albedo increase in mountainous areas according to different experimental data and model simulations. The error bars of model simulation relate to the different input parameters - altitude of 2 and $3 \mathrm{~km}$, solar elevation of 10,30 and $50^{\circ}$, total ozone $X=350 \mathrm{DU}, \mathrm{AOD}_{340}=0.17$ at $P=95 \%$.

the account of overall interactions between radiation and different surfaces. The comparisons of UV spectral actinic flux measurements with 1-D and 3-D model simulations demonstrate the similar range of uncertainties of these models, however, 3-D model gives, of course, more realistic view of the UV field in mountains since the topography and the obstruction of the horizon are taken into account (Wagner et al., 2011). However, currently we do not consider 3-D effects in our parameterization. Due to small UV albedo over snow free surfaces this factor is negligible in summer, while in winter the value of the effective surface albedo in mountainous area can be very high and significantly depends on tree line location.

To account for surface albedo effects we followed the results obtained in different papers (Green et al., 1980; Chubarova, 1994), where the effects of multiple scattering were accounted using geometric progression approach. The same approach with a detailed physical analysis was used in Lenoble (1998). Following these publications we propose to calculate biologically active UV radiation in conditions with surface albedo $S$ as follows:

$Q_{\text {bios }_{S}}=Q_{\text {bio }_{S=0}} \frac{1}{1-r_{\text {bio }} S}$,

where $r_{\text {bio }}$ is the coefficient, which characterizes the maximum relative change in $Q_{\text {bio }}$ due to multiple scattering for surface albedo variations from 0 to 1 . According to Lenoble (1998) $r_{\text {bio }}$ is determined as the atmospheric reflectance illuminated on its lower boundary. Note, that surface albedo $S$ characterizes the reflecting properties at ground at the considered altitude $H$.

The application of the Eq. (17) to $H=0 \mathrm{~km}$ and to the altitude $H$ allows us to obtain the following expression for $Q_{\text {bio }}$ at $H$ with surface albedo $S_{H}$ : using the known $Q_{\text {bio }}$ at the altitude $H=0 \mathrm{~km}$ with surface albedo $S_{0}$ : 


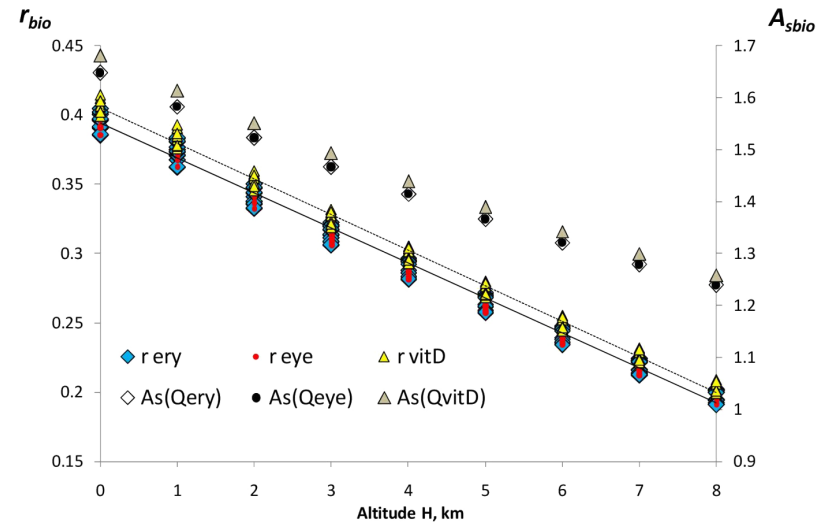

Figure 6. The dependence of $r_{\text {bio }}$ with the altitude for different BAUVR from accurate model simulations for a variety of geophysical parameters (left axis) and maximum $A_{S}$ effects due to changes in surface albedo from $S=0$ at $H=0 \mathrm{~km}$ to $S=1$ at level $H$ (right axis). The $r_{\text {bio }}$ regressions are shown in dashed line. Note, that the regression line for $r_{Q_{\text {eye }}}(H)$ is the same as for $r_{Q_{\text {ery }}}(H)$. The coefficients of the regression equations and the ranges of the input parameters at $H=0$ are given in Table 2 .

$$
\begin{aligned}
& Q_{\text {bio }_{S}}(H)=Q_{\text {bio }_{S_{0}}}(H=0) \frac{Q_{\text {bio }_{S=0}}(H)}{Q_{\text {bio }_{S=0}}(H=0)} \\
& \frac{1-r_{\text {bio }}(H=0) S_{0}}{1-r_{\text {bio }}(H) S_{H}}
\end{aligned}
$$

This equation can be rewritten in the following way:

$$
\begin{aligned}
& \frac{Q_{\text {bio }_{H}}(H)}{Q_{\text {bio }_{0}}(H=0)}=\frac{Q_{\text {bio }_{S=0}}(H)}{Q_{\text {bio }_{S=0}}(H=0)} \\
& \quad \frac{1-r_{\text {bio }}(H=0) S_{0}}{1-r_{\text {bio }}(H) S_{H}}
\end{aligned}
$$

One can see that in Eq. (19) the left side of the equation $\frac{Q_{\text {bio }_{H}}(H)}{Q_{\text {bio }_{0}}(H=0)}$ is the total UV amplification $A_{\mathrm{UV}}$ defined in Eq. (4); the first term $\left(\frac{Q_{\text {bio }_{S=0}}(H)}{Q_{\text {bio }_{S=0}}(H=0)}\right)$ at the right side of the equation characterizes the total UV amplification in conditions with $S=0$, while surface albedo effects are accounted only in the last term. Hence, we can write the UV amplification due to the effects of surface albedo as follows:

$A_{S}=\frac{1-r_{\text {bio }}(H=0) S_{0}}{1-r_{\text {bio }}(H) S_{H}}$

According to the model estimations the value $r_{\text {bio }}$ in clear sky conditions has the dependence on altitude, which appears due to a decrease mainly in molecular and aerosol loading and can be parameterized by a simple regression as follows:

$r_{\text {bio }}(H)=b H+c$,
Table 2. The coefficients for calculating the $r_{\text {bio }}$ values (Eq. 21) for different types of BAUVR. Model estimations. The standard error of the coefficients is given in the brackets at $P=95 \%$.

\begin{tabular}{lrrr}
\hline & $\begin{array}{r}\text { Erythemally- } \\
\text { weighted } \\
\text { irradiance }\end{array}$ & $\begin{array}{r}\text { Cataract- } \\
\text { weighted } \\
\text { irradiance }\end{array}$ & $\begin{array}{r}\text { Vitamin } \\
\text { D-weighted } \\
\text { irradiance }\end{array}$ \\
\hline$b$ & $-0.025(0.0002)$ & $-0.025(0.0002)$ & $-0.025(0.0002)$ \\
$c$ & $0.394(0.0009)$ & $0.394(0.0009)$ & $0.405(0.0008)$ \\
$R^{2}$ & $>0.99$ & $>0.99$ & $>0.99$ \\
\hline
\end{tabular}

Note: the simulations were fulfilled for different combinations of input parameters at $H=0: X=250-350 \mathrm{DU}, \mathrm{AOD}_{340}=0.2-0.4, S=0-0.9, h=20-50^{\circ}$.

where the coefficients $b$ and $c$ are given in Table 2 for different types of BAUVR. They were obtained for a variety of solar elevation and ozone content taking into account for the altitude changes in molecular scattering as well as for altitude dependence of aerosol optical depth $f_{\mathrm{AOD}}(H)$. The $r_{\mathrm{bio}(H)}$ mainly depends on molecular content and aerosol properties, and slightly decreases with the altitude due to reducing in multiple scattering effects with the decrease in molecular and aerosol loading.

As a result, the UV amplification due to the increase in surface albedo at the altitude $H$ strongly depends on scattering processes and also decreases with the altitude. Figure 6 shows the maximum $A_{S}$ effect due to the changes in $S$ from $S=0$ at zero level to $S=1$ at the altitude $H$ for the different types of BAUVR. The $A_{S}$ decreases with the altitude from more than 1.6 at $H=0 \mathrm{~km}$ to about 1.2 at $H=8.848 \mathrm{~km}$ due to the decrease in $r_{\text {bio. }}$.

\subsection{Validation}

Using the generalized parameterizations for different geophysical parameters obtained in the previous sections we can estimate the total UV amplification $A_{\mathrm{UV}}$ with the altitude from Eq. (4). The results of the validation of the proposed method with these altitude parameter dependencies against the accurate RT simulations are shown in Fig. 7. One can see a high correlation $(r>0.996)$ between the $A_{\mathrm{UV}}$ values obtained by the proposed method and the accurate RT simulations using the 8-stream DISORT method within the changes in altitude from $H=0$ to $8 \mathrm{~km}$, in solar elevation from 20 to $50^{\circ}$, in surface albedo from $S=0$ to $S=0.9$, in ozone from 250 to $350 \mathrm{DU}$ at $H=0 \mathrm{~km}$, in $\mathrm{AOD}_{340}$ from 0.2 to 0.4 at $H=0 \mathrm{~km}$, and in SSA varying from 0.88 to 0.96 . Different altitude aerosol profiles were also considered. Validation was made for all three types of BAUVR. Overall, the average bias is $0 \pm 2 \%$ for erythemally weighted irradiance, $0 \pm 1 \%$ - for cataract-weighted, and $1 \pm 1 \%$ - for vitamin $\mathrm{D}$ irradiance. The maximum difference between the $A_{\mathrm{UV}}$ calculated by the proposed method and by the accurate model simulations does not exceed $6 \%$ at the highest elevation $(H=8 \mathrm{~km})$ at low ozone content. 


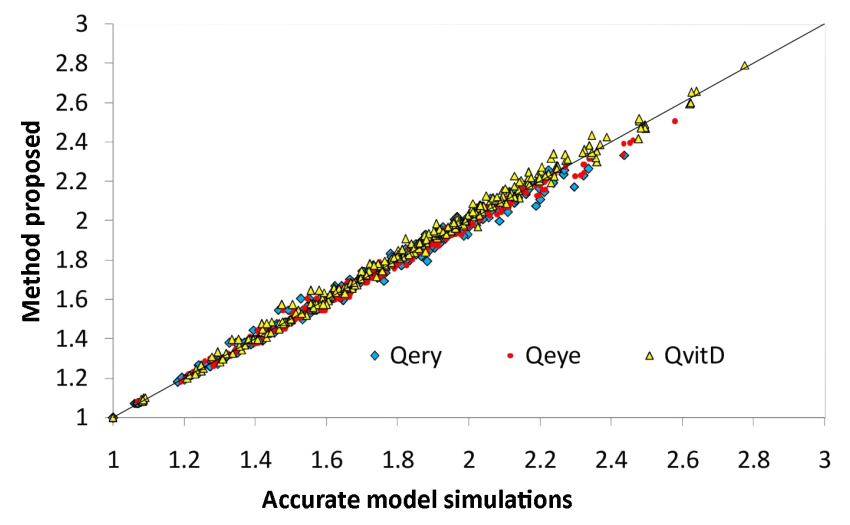

Figure 7. The comparison between the total altitude UV amplification according to the proposed method and the $A_{\mathrm{UV}}$ values evaluated using the accurate RT model (TUV, 8-stream DISORT method). See the details in the text.

The comparisons of the total UV amplification according to the proposed method with the total $A_{\mathrm{UV}}$ obtained from the experimental data set as a function of altitude are shown in Fig. 8. The experimental data were taken from the data set of Moscow State University mountainous field campaigns, which was described in the Sect. 2. After accounting for the molecular, aerosol, and ozone altitude dependence the simulated UV amplification is in satisfactory agreement with the obtained experimental results.

\section{Discussion}

The total altitude amplification of biologically active UV irradiance $A_{\mathrm{UV}}$ as a function of altitude is shown in Fig. 9 for a variety of atmospheric conditions at surface albedo $S=0$ and $S=0.9$ and high solar elevation $h=50^{\circ}$. One can see a distinct altitude difference obtained for different types of BAUVR with larger increase for vitamin D-weighted irradiance due to its higher sensitivity to ozone content. The difference in $A_{\mathrm{UV}}$ for various BAUVR can reach $15-20 \%$ at high altitudes. The effects of surface albedo on $A_{\mathrm{UV}}$ can be seen if we compare the results shown in Fig. 9a and b. One can see the 2-2.5 times UV increase due to high surface albedo at high altitudes, which is again more pronounced for vitamin D-weighted radiation with smaller effective wavelength and, hence, more effective multiple scattering than that for the other types of BAUVR. Larger $A_{\mathrm{UV}}$ values are also observed in conditions with smaller ozone amount for all three types of BAUVR for both zero and high surface albedo conditions. High surface albedo $S=0.9$ provides a significant increase even at zero level, which is similar to the $A_{\mathrm{UV}}$ increase due to altitude change of $6 \mathrm{~km}$. It is clearly seen that typical aerosol and ozone does not play a vital role in $A_{\mathrm{UV}}$. However, for all types of BAUVR the increase of slightly absorbing aerosol (from $\mathrm{AOD}_{340}=0.2$ to $\mathrm{AOD}_{340}=0.4$ ) pro-

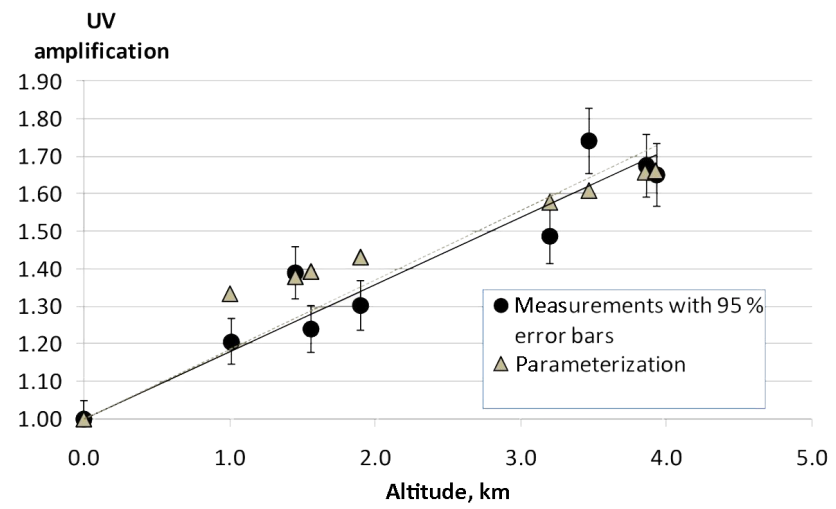

Figure 8. The comparison between the simulated UV amplification according to the proposed parameterization and the UV amplification from the experimental data as a function of altitude. Moscow State University data set. Solar elevation $h=50^{\circ}$. Clear sky conditions. Note: since we used the data of different field campaigns the ozone altitude gradient differed from the typical value. The total ozone was equal to $X \sim 300 \mathrm{DU}$ at $H=0 \mathrm{~km}, X \sim 240 \mathrm{DU}$ at $H>3 \mathrm{~km}$ and $X \sim 250 \mathrm{DU}$ at $H \sim 1-2 \mathrm{~km}$.

vides a noticeable $A_{\mathrm{UV}}$ growth in conditions with relatively small ozone content due to enhancement of multiple scattering (see Fig. 9).

The $A_{\mathrm{UV}}$ values are smaller at solar elevation $h<20^{\circ}$ for all types of BAUVR mainly due to decreasing in $G_{\text {bio }_{M}}$ (see the coefficients in Table 1). For example, at $H=8 \mathrm{~km}$ the UV altitude amplification for vitamin D-weighted radiation is about $A_{\mathrm{UV}}=1.77$ at $h=10^{\circ}$ compared with $A_{\mathrm{UV}}=2.0$ at $h=50^{\circ}$ at $X=250 \mathrm{DU}$ and $\mathrm{AOD}_{340}=0.4$.

Let us consider the conditions, which are characterized by the most pronounced UV amplification with the altitude the conditions with high aerosol loading $\mathrm{AOD}_{340}=0.8$, low ozone content $X=250 \mathrm{DU}$ at $H=0 \mathrm{~km}$, and high solar elevation $h=50^{\circ}$. In addition, we consider the abrupt increase in surface albedo at $H=2 \mathrm{~km}$ from $S \sim 0$ to $S=0.95$, which can be possible due to location of tree line there and pure snow above. The altitude UV amplification due to these input parameters according to the proposed $A_{\mathrm{UV}}$ parameterization is shown in Fig. 10. The separate effects of different factors can be seen in Fig. 10a and their total effects on different BAUVR types are shown in Fig. 10b. One can see a different role of geophysical factors at different altitudes: the prevalence of molecular scattering especially at high altitudes while the extremely high surface albedo may play the most important role at the altitudes of its abrupt increase (in our case $-H=2 \mathrm{~km}, A_{S}=1.48$ ). However, in our example the UV amplification due to surface albedo decreases at the altitude higher than $2 \mathrm{~km}$ because of the reduction in multiple scattering. The UV altitude amplification due to aerosol is more distinct and reaches 1.1-1.2 at high altitudes if there is a strong aerosol pollution $\mathrm{AOD}_{340}=0.8$ at $H=0 \mathrm{~km}$. It is more pronounced for the Alpine-type AOD altitude depen- 

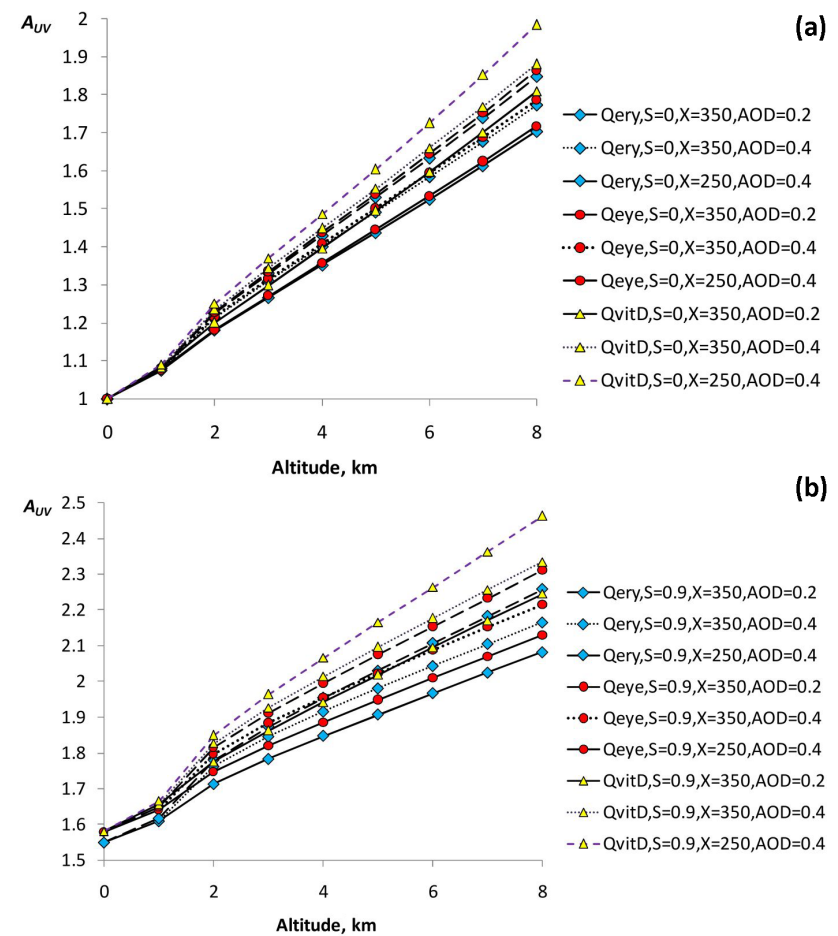

Figure 9. Total UV amplification as a function of the altitude for different types of BAUVR in a variety of atmospheric conditions with $S=0$ (a) and $S=0.9$ (b). The model parameters at $H=0 \mathrm{~km}$ : $X=250-350 \mathrm{DU}, \mathrm{AOD}_{340}=0.2-0.4$. The Alpine type of AOD altitude dependence according to the Eq. (15) was taken into account. Solar elevation $h=50^{\circ}$.

dence and in our example at $H=2 \mathrm{~km}$ it can be even higher than the $A_{M}$ value (see Fig. 10). The effects of ozone in UV amplification do not exceed 1.1-1.2 at high altitudes depending on BAUVR type. We would like to emphasize that Fig. 10 is only the illustration of the application of the proposed $A_{\mathrm{UV}}$ parameterization for a given parameters altitude variations.

We implemented the proposed UV altitude parameterization in the developed on-line UV tool http://momsu.ru/uv/, which had been developed for the simulation of erythemally weighted irradiance and the UV resources over Northern Eurasia (the PEEX domain) at $H=0 \mathrm{~km}$ (Chubarova and Zhdanova, 2013). Using this program it is possible to calculate UV irradiance and UV-resources for different atmospheric conditions at a given geographic location and specified time. Based on the threshold for vitamin D and erythemally active irradiance the UV resources are obtained for various skin types and open body fraction. According to the classification we consider different categories of UVdeficiency, UV-optimum and UV-excess (Chubarova and Zhdanova, 2013). The interactive on-line UV tool represents a client-server application where the client part of the program is the web-page with a special form for the input parameters required for erythemally weighted UV irradiance simulations. The server part of the program consists of the web-
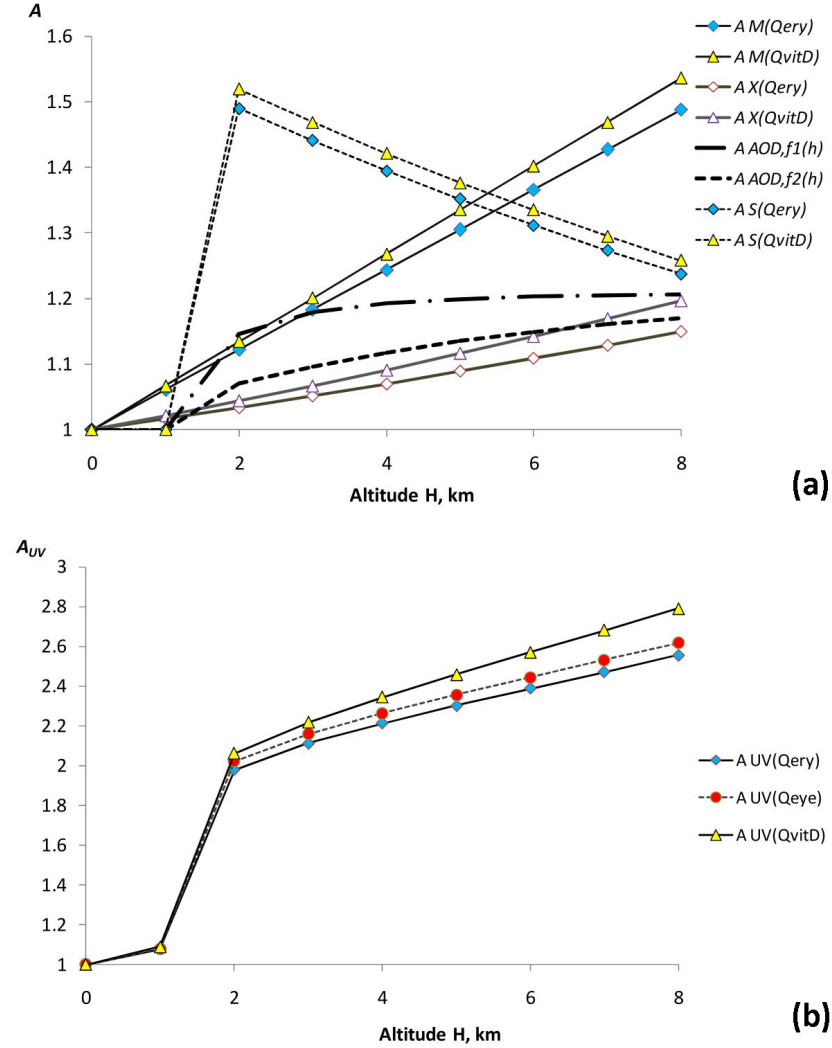

Figure 10. The UV amplification due to molecular $A_{M}\left(Q_{\text {ery }}\right)$, $A_{M}\left(Q_{\mathrm{vitD}}\right)$, ozone $A_{X}\left(Q_{\mathrm{vitD}}\right), A_{X}\left(Q_{\text {ery }}\right)$, aerosol $A_{\mathrm{AOD}, f 1(H)}$, $A_{\mathrm{AOD} f 2(H)}$ for the Alpine $f 1(H)$ and Asian $f 2(H)$ types of altitude dependences, and surface albedo $A_{S}\left(Q_{\text {ery }}\right), A_{S}\left(Q_{\text {vitD }}\right)$ changes with the altitude (a) and their total altitude effect on $A_{\mathrm{UV}}$ for different types of BAUVR (b). At $H=0 \mathrm{~km}$ : $\mathrm{AOD}_{340}=0.8$, $X=250 \mathrm{DU}$. The surface albedo has an abrupt change at $2 \mathrm{~km}$ from $S=0$ to $S=0.95$. Solar elevation $-h=50^{\circ}$.

server and the CGI-script, where the different input parameters are set by a user or taken from the climatological data available at the same site. In addition, in this part of the program erythemally weighted irradiance is calculated, visualized and classified according to the proposed UV resources categories. The proposed UV irradiance altitude parameterization has been also incorporated in the calculation scheme with additional account for the changes in the atmospheric parameters with the height. This enables a user to evaluate UV irradiance at any requested elevation above sea level taking into account for a variety of the altitude-dependent parameters.

Let us analyze the UV resources for skin type 2 and the open body fraction of 0.25 in the Alpine region (approximately $46^{\circ} \mathrm{N}$ and $7^{\circ} \mathrm{E}$ ) for winter and spring noon conditions. For these conditions the vitamin $\mathrm{D}$ threshold is equal to $100 \mathrm{~J} \mathrm{~m}^{-2}$ and Minimal Erythemal Dose $-250 \mathrm{~J} \mathrm{~m}^{-2}$. According to our estimates on 15 January, at $H=0 \mathrm{~km}$ for typical (climatological) ozone, aerosol and surface albedo 
conditions the noon UV deficiency (no vitamin D generation) is observed with noon erythemally UV dose of about $97.2 \mathrm{~J} \mathrm{~m}^{-2}$, while at the same coordinates at $H$ higher $0.5 \mathrm{~km}$ up to $H=4.8 \mathrm{~km}$ (the highest point within the Alps, peak Mont Blanc) we obtain the UV optimum conditions with noon erythemal UV dose varying from 100.6 to $122.9 \mathrm{~J} \mathrm{~m}^{-2}$.

However, for skin type 4 (Fitzpatrick, 1988) with vitamin $\mathrm{D}$ threshold of $180 \mathrm{~J} \mathrm{~m}^{-2}$ the noon UV deficiency is observed at all altitudes and even at high surface albedo $S=0.9$ corresponding to the pure snow with UV dose of $154.4 \mathrm{~J} \mathrm{~m}^{-2}$. The decrease in open body fraction for this skin type from 0.25 to 0.05 , which could take place in frosty weather, provides $100 \%$ UV deficiency, when no vitamin D can be generated during the whole day at the $H=4.8 \mathrm{~km}$ and $S=0.9$.

On 15 April at $H=0 \mathrm{~km}$ and typical climatological conditions at this geographical point noon UV dose is about $437.7 \mathrm{~J} \mathrm{~m}^{-2}$. This means that for the open body fraction of 0.4 the moderate UV excess is observed for skin type 2 and the UV optimum - for skin type 4, when vitamin D threshold is $112.5 \mathrm{~J} \mathrm{~m}^{-2}$ and MED threshold $-450 \mathrm{~J} \mathrm{~m}^{-2}$. At the altitude $H=2 \mathrm{~km}$ the conditions are characterized by the moderate UV excess for both skin types 2 and 4 with UV dose of $463.4 \mathrm{~J} \mathrm{~m}^{-2}$. At the $H=4 \mathrm{~km}$ a high UV excess is observed for skin type 2 and the moderate UV excess - for skin type 4 with UV dose of $532.4 \mathrm{~J} \mathrm{~m}^{-2}$.

Thus, the proposed altitude UV parameterization can be effectively used for accurate estimating the BAUVR at different altitudes with any altitude resolution for a variety of geophysical parameters over the PEEX domain in Northern Eurasia. The accurate RT methods like Monte-Carlo, Discrete Ordinate method or others, of course, can be used instead for UV irradiance simulations, however, their application is very time-consuming and are not possible in some applications. The proposed approach is especially very useful for the application in different kinds of on-line UV tools, where it is not possible to use a lot of prescribed calculations for a wide set of different geophysical parameters or accurate UV modelling.

The current state of the online interactive tool does not take into account for the skin orientation relative to the Sun and the geometry of the human body which can modify the results limited to UV irradiance simulations on horizontal surface (Hess and Koepke, 2008; Vernez et al., 2014). In this case UV dosimeters which have a spectral response almost identical to that of the UV-induced photobiological effect (Siani et al., 2008) is the most accurate way for evaluating the individual levels of UV exposure. The vitamin D production can be also affected by other factors such as obesity and age (Engelsen, 2010). However, these are the tasks for the future work.

The combination of different altitude dependencies for main geophysical factors in the proposed parameterization allows a user to make a reliable altitude UV assessment. We should also emphasize that the proposed ozone and aerosol altitude dependencies in the troposphere were taken from the experimental data obtained in background conditions and, hence, should be applied only for these conditions. However, they can be easily substituted by any other altitude dependence of considering factors.

With the application of the proposed method we can also reveal the effects of different geophysical factors on various types of BAUVR and estimate their comparative role in the altitude UV effects. And, of course, the parameterization can be also used in downscaling the UV results from the coarse resolution global chemistry-climate models for the regions located at high altitudes. The proposed method can be applied not only over the PEEX domain but on a global scale over the world. However, more attention should be paid in this case to the evaluation of the particular altitude dependence of the different parameters.

\section{Conclusions}

The objective of this paper was to develop a flexible parameterization based on rigorous model simulations with account for generalized altitude dependencies of molecular density, ozone, and aerosols considering different surface albedo conditions. We show that for the specified groups of parameters we can present the altitude UV amplification $\left(A_{U V}\right)$ for different BAUVR as a composite of independent contributions of UV amplification from different factors with the mean uncertainty of $1 \%$ and standard deviation of $3 \%$. The parameterization takes into account for the altitude dependence of molecular number density, ozone content, aerosol loading, and spatial surface albedo. We also provide the generalized altitude dependencies of different parameters for evaluating the $A_{\mathrm{UV}}$. Their validation against the accurate RT model (8 stream DISORT RT code) for different types of BAUVR shows a good agreement with maximum uncertainty of few percents and correlation coefficient $r>0.996$. It was not possible, of course, to cover all the observed variety in the parameters. However, due to the proposed approach the parameter altitude dependencies can be easily substituted by a user.

Using this parameterization one can estimate the role of different atmospheric factors in the altitude UV variation. The decrease in molecular number density, especially at high altitudes, and the increase in surface albedo play the most significant role in $A_{\mathrm{UV}}$ growth. At high solar elevations the UV amplification due to aerosol at $H=8.848 \mathrm{~km}$ does not exceed 1.3 even when $\mathrm{AOD}_{340}=0.8$ at $H=0 \mathrm{~km}$. The UV amplification due to aerosol calculated with the Alpine-type AOD altitude aerosol dependence is much more pronounced than that calculated with the Asian-type AOD altitude dependence, especially at relatively lower altitudes $(H=2-4 \mathrm{~km})$. The UV amplification due to ozone does not exceed 1.20 and is higher at smaller solar elevations, especially, for vitaminD-weighted irradiance. 
This parameterization was applied to the on-line tool for calculating the UV resources (http:/momsu.ru/uv/) over the PEEX domain. Using this tool one can easily evaluate the UV conditions (UV deficiency, UV optimum or UV excess) at different altitudes for a given skin type and open body fraction. As an example, we analyzed the altitude UV increase and its possible effects on health considering different skin types and various open body fraction for January and April conditions in the Alpine region. We showed that even in clear sky conditions over the same geographical point $\left(46^{\circ} \mathrm{N}\right.$, $7^{\circ} \mathrm{E}$ ) in mid-January the UV optimum can be observed at altitudes higher than $H=0.5 \mathrm{~km}$ for skin type 2, while the noon UV deficiency are still remained at the altitudes up to $H=4.8 \mathrm{~km}$ for skin type 4 when open body fraction is 0.25 . In mid-April the account for the altitude dependence at $4 \mathrm{~km}$ provides the changes from the moderate UV excess to a high UV excess for skin type 2 and from UV-optimum the moderate UV excess - for skin type 4 when open body fraction is 0.4 .

This approach can be also used in downscaling the results of global chemistry-climate models with the coarse spatial resolution in mountainous domain and as a simple tool for different types of applications for personal purposes of users.

\section{Data availability}

All simulations were fulfilled with radiative TUV (tropospheric ultraviolet-visible) model (Madronich and Flocke, 1997) (https://www2.acom.ucar.edu/modeling/ tropospheric-ultraviolet-and-visible-tuv-radiation-model).

For obtaining aerosol optical depth we used the data of sun/sky CIMEL photometers from different AERONET sites (Holben et al., 1998) (http://aeronet.gsfc.nasa.gov/). We used the LIVAS database (Lidar Climatology of Vertical Aerosol Structure for Space-Based Lidar Simulation Studies, http://lidar.space.noa.gr:8080/livas/). The suggested parameterization of the UV irradiance altitude dependence implemented in the online UV tool (http://momsu.ru/uv/).

Acknowledgements. The work was partially supported by the RFBR grant no. 15-05-03612. We would like to thank all AERONET site PI's which data were used for obtaining the aerosol altitude dependence. We also are grateful to the LIVAS team for providing the aerosol extinction climatology.

Edited by: V.-M. Kerminen

Reviewed by: three anonymous referees

\section{References}

Amiridis, V., Marinou, E., Tsekeri, A., Wandinger, U., Schwarz, A., Giannakaki, E., Mamouri, R., Kokkalis, P., Binietoglou, I., Solomos, S., Herekakis, T., Kazadzis, S., Gerasopoulos, E., Proestakis, E., Kottas, M., Balis, D., Papayannis, A., Kontoes, C.,
Kourtidis, K., Papagiannopoulos, N., Mona, L., Pappalardo, G., Le Rille, O., and Ansmann, A.: LIVAS: a 3-D multi-wavelength aerosol/cloud database based on CALIPSO and EARLINET, Atmos. Chem. Phys., 15, 7127-7153, doi:10.5194/acp-15-71272015, 2015.

Arola, A., Kazadzis, S., Lindfors, A., Krotkov, N., Kujanpää, J., Tamminen, J., Bais, A., di Sarra, A., Villaplana, J. M., Brogniez, C., Siani, A. M., Janouch, M., Weihs, P., Webb, A., Koskela, T., Kouremeti, N., Meloni, D., Buchard, V., Auriol, F., Ialongo, I., Staneck, M., Simic, S., Smedley, A., and Kinne, S.: A new approach to correct for absorbing aerosols in OMI UV, Geophys. Res. Lett., 36, L22805, doi:10.1029/2009GL041137, 2009.

Badosa, J., McKenzie, R. L., Kotkamp, M., Calbó, J., González, J. A., Johnston, P. V., O’Neill, M., and Anderson, D. J.: Towards closure between measured and modelled UV under clear skies at four diverse sites, Atmos. Chem. Phys., 7, 2817-2837, doi:10.5194/acp-7-2817-2007, 2007.

Bais, A. F., Lubin, D., Arola, A., Bernhard, G., Blumthaler, M., Chubarova, N., Erlick, C., Gies, H. P., Krotkov, N., Mayer, B., McKenzie, R. L., Piacentini, R., Seckmeyer, G., and Slusser, J. R.: Surface Ultraviolet Radiation: Past, Present, and Future, in: Scientific Assessment of Ozone Depletion: 2006, Global Ozone Research and Monitoring Project - Report No. 50, World Meteorological Organization, Geneva, Switzerland. Chapter 7, 54 pp., 2007.

Barnard, J. C., Volkamer, R., and Kassianov, E. I.: Estimation of the mass absorption cross section of the organic carbon component of aerosols in the Mexico City Metropolitan Area, Atmos. Chem. Phys., 8, 6665-6679, doi:10.5194/acp-8-6665-2008, 2008.

Bekki, S., Bodeker, G. E., Bais, A. F., Butchart, N., Eyring, V., Fahey, D. W., Kinnison, D. E., Langematz, U., Mayer, B., Portmann, R. W., Rozanov, E., Braesicke, P., Charlton-Perez, A. J., Chubarova, N. E., Cionni, I., Diaz, S. B., Gillett, N. P., Giorgetta, M. A., Komala, N., Lefèvre, F., McLandress, C., Perlwitz, J., Peter, T., and Shibata, K.: Future Ozone and Its Impact on Surface UV, in: Scientific Assessment of ozone Depletion: 2010, Global Ozone Research and Monitoring Project - Report 52, World Meteorological Organization, Geneva, Switzerland, Chapter 3, 60 pp., 2011.

Belinsky, V. A., Garadzha, M. P., Mezhennaya, L. M., and Nezval', Ye. I.: The Ultraviolet Radiation of Sun and Sky, edited by: Belinsky, V. A., Moscow State Univ. Press. Moscow, 226 pp., 1968 (in Russian).

Bernhard, G., Booth, C. R., and Ehramjian, J. C.: Comparison of UV irradiance measurements at Summit, Greenland; Barrow, Alaska; and South Pole, Antarctica, Atmos. Chem. Phys., 8, 4799-4810, doi:10.5194/acp-8-4799-2008, 2008.

Blumthaler, M. and Ambach, W.: Human solar ultraviolet radiant exposure in high mountains, Atmos. Environ., 22, 749-753, 1988.

Blumthaler, M., Webb, A. R., Seckmeyer, G., Bais, A. F., Huber, M., and Mayer, B.: Simultaneous spectroradiometry: A study of solar UV irradiance at two altitudes, Geophys. Res. Lett., 21, 28052808, doi:10.1029/94GL02786, 1994.

Blumthaler, M., Ambach, W., and Ellinger, R.: Increase in the UV radiation with altitude, J. Photochem. Photobiol. B, 39, 130-134, 1997.

Booth, C. R. and Madronich, S.: Radiation amplification factors: Improved formulation accounts for large increases in ultraviolet 
radiation associated with Antarctic ozone depletion, in: Ultraviolet Radiation in Antarctica: Measurements and Biological Effects, Antarct. Res. Ser., edited by: Weiler, C. S. and Penhale, P. A., 62, AGU, Washington, D.C., 39-42, 1994.

Bornman, J. F., Paul, N., and Tang, X.: Environmental Effects Of Ozone Depletion And Its Interactions With Climate Change: 2010 Assessment, Photochem. Photobiol. Sci., 10, 165-320, 2011.

Bornman, J. F., Paul, N., and Shao, M.: Environmental Effects Of Ozone Depletion And Its Interactions With Climate Change: 2014 Assessment, Photochem. Photobiol. Sci., 14, 1-184, 2015.

Bouillon, R., Eisman, J., Garabedian, M., Holick, M., Kleinschmidt, J., Suda, T., Terenetskaya, I., and Webb, A.: Action Spectrum for the Production of Previtamin D3 in Human Skin, Technical Report 174, CIE, Vienna, Austria, 16 pp., 2006.

Casale, G. R., Siani, A. M., Diémoz, H., Agnesod, G., Parisi, A. V., and Colosimo, A.: Extreme UV Index and Solar Exposures at Plateau Rosà (3500 m a.s.l) in Valle d'Aosta Region, Italy, Sci. Total Environ., 512, 622-630, 2015.

Chubarova, N. and Nezval', Ye.: Thirty year variability of UV irradiance in Moscow, J. Geophys., Res.-Atmos., 105, 12529-12539, 2000.

Chubarova, N. and Zhdanova, Ye.: Ultraviolet resources over Northern Eurasia, J. Photoch. Photobio. B, 127, 38-51, 2013.

Chubarova, N. Y.: Seasonal distribution of aerosol properties over Europe and their impact on UV irradiance, Atmos. Meas. Tech., 2, 593-608, doi:10.5194/amt-2-593-2009, 2009.

Chubarova, N. Ye.: The transmittance of the Global Ultraviolet Radiation by Different Cloud Types, Izv. Atmos. Ocean Phys., 29, 615-621, 1994.

Dahlback, A., Gelsor N., Stamnes J. J., and Gjessing Y.: UV measurements in the 3000-5000 $\mathrm{m}$ altitude region in Tibet, J. Geophys. Res., 112, D09308, doi:10.1029/2006JD007700, 2007.

Diémoz, H. and Mayer, B.: UV radiation in a mountainous terrain: comparison of accurate 3D and fast $1 \mathrm{D}$ calculations in terms of UV index, in: One Century of UV Radiation Research, edited by: Gröbner, J., Davos, Switzerland, 18-20 September 2007, 165166, 2007.

Diffey, B. L., Jansen, C. T., Urbach, F., and Wulf, H. C.: Erythema reference action spectrum and standard erythema dose, CIE Standard, ISO 17166:1999(E)/CIES007-1998, Vienna, Austria, 4 pp., 1998.

Engelsen, O.: The Relationship between Ultraviolet Radiation Exposure and Vitamin D Status, Nutrients, 2, 482-495, doi:10.3390/nu2050482, 2010.

Feister, U. and Grewe, R.: Spectral albedo measurements in the UV and visible region over different types of surfaces, J. Photoch. Photobio., 62, 736-744, 1995.

Fitzpatrick, T. B.: The validity and practicality of sun-reactive skin types I through VI, Arch. Dermatol., 124, 869-871, 1988.

Green, A. E. S., Cross, K. R., and Smith, L. A.: Improved analytic characterization of ultraviolet skylight, J. Photoch. Photobio., 31, 59-65, 1980.

Herman, J. R.: Global increase in UV irradiance during the past 30 years (1979-2008) estimated from satellite data, J. Geophys. Res., 115, D04203, doi:10.1029/2009JD012219, 2010.

Hess, M. and Koepke, P.: Modelling UV irradiances on arbitrarily oriented surfaces: effects of sky obstructions, Atmos. Chem. Phys., 8, 3583-3591, doi:10.5194/acp-8-3583-2008, 2008.
Holben, B. N., Eck, T. F., Slutsker, I., Tanre, D., Buis, J. P., Setzer, A., Vermote, E., Reagan, J. A., Kaufman, Y. J., Nakajima, T., Lavenu, F., Jankowiak, I., and Smirnov, A.: AERONET - A federated instrument network and data archive for aerosol characterization, Remote Sens. Environ., 66, 1-16, 1998.

Holben, B. N., Eck, T., Slutsker, I., Smirnov, A., Sinyuk, A., Schafer, J., Giles, D., and Dubovik, O.: AERONET Version 2.0 quality assurance criteria, in: Remote Sensing of the Atmosphere and Clouds, edited by: Tsay, S.-C., Nakajima, T., Singh, R. P., and Sridharan, R., Proceedings of SPIE, Goa, 13-17 November 2006, India, 6408, 2006.

Huber, M., Blumthaler, M., Schreder, J., Schallhart, B., and Lenoble, J.: Effect of inhomogeneous surface albedo on diffuse UV sky radiance at a high-altitude site, J. Geophys. Res., 109, D08107, doi:10.1029/2003JD004013, 2004.

Hülsen, G.: UV measurements at mountain sites, PMOD WRC Annual report, 36 pp., 2012.

Gröbner, J., Hülsen, G., and Blumthaler, M.: Effect of snow albedo and topography on UV radiation, in: Proceedings of 2010 UV workshop, New Zealand, 2010.

Lenoble, J.: Modeling of the influence of snow reflectance on ultraviolet irradiance for cloudless sky, Appl. Optics, 37, 2441-2447, 1998.

Lenoble, J., Kylling, A., and Smolskaia, I.: Impact of snow cover and topography on ultraviolet irradiance at the Alpine station of Briancon, J. Geophys. Res., 109, D16209, doi:10.1029/2004JD004523, 2004.

Liou, K. N.: An Introduction to Atmospheric Radiation, International Geophysics Series, Academic press, 84, 583 pp., 2010.

Lityńska, Z., Koepke, P., De Backer, H., Gröbner, J., Schmalwieser, A., and Vuilleumier, L. (Eds.): Long Term Changes and Climatology of UV Radiation over Europe, COST Action 726 - Final Scientific Report, Luxembourg: Publications Office of the European Union, 2012.

Madronich, S.: The atmosphere and UV-B radiation at ground level, in: Environmental UV Photobiology, edited by: Young, A. R., Moan, J., Björn, L. O., and Nultsch, W., Springer US, 1-39, 1993.

Madronich, S. and Flocke, S.: Theoretical estimation of biologically effective UV radiation at the Earth's surface, in: Solar Ultraviolet Radiation - Modeling, Measurements and Effects, edited by: Zerefos, C. and Bais, A. F., NATO ASI Series, 152, SpringerVerlag, Berlin, 23-48, 1997.

McKenzie, R., Blumthaler, M., Diaz, S., Fioletov, V., Herman, J., Seckmeyer, G., Smedley, A., and Webb, A.: Rationalizing nomenclature for UV doses and effects on humans, CIE 209:2014, WMO/GAW Report\#211, 14 pp., 2014.

McKenzie, R. L., Liley, J. B., and Bjorn, L. O.: UV Radiation: Balancing Risks and Benefits, J. Photochem. Photobiol., 85, 88-98, 2009.

Norval, M., Bjorn, L. O., and de Gruijl, F. R.: Is the action spectrum for the UV-induced production of previtamin D3 in human skin correct, Photochem. Photobiol. Sci., 9, 11-17, 2010.

Oriowo, O. M., Cullen, A. P., Chou, B. R., and Sivak, J. G.: Action spectrum for in vitro UV-induced cataract using whole lenses, Invest. Ophthalmol. Vis. Sci., 42, 2596-2602, 2001.

Panchenko, M. V., Zhuravleva, T. B., Terpugova, S. A., Polkin, V. V., and Kozlov, V. S.: An empirical model of optical and radiative characteristics of the tropospheric aerosol over West Siberia in 
summer, Atmos. Meas. Tech., 5, 1513-1527, doi:10.5194/amt5-1513-2012, 2012.

Pfeifer, M. T., Koepke, P., and Reuder, J.: Effects of altitude and aerosol on UV radiation, J. Geophys. Res., 111, D01203, doi:10.1029/2005JD006444, 2006.

Piacentini, R. D., Cede, A., and Bárcena, H.: Extreme solar total and UV irradiances due to cloud effect measured near the summer solstice at the high-altitude desertic plateau Puna of Atacama (Argentina), J. Atmos. Sol.-Terr. Phy., 65, 727-731, 2003.

Reuder, J. and Koepke, P.: Reconstruction of UV radiation over southern Germany for the past decades, Meteorol. Z., 14, $237-$ 246, 2005.

Reuder, J., Ghezzi, F., Palenque, E., Torrez, R., Andrade, M., and Zaratti, F.: Investigations of the effect of high surface albedo on erythemally effective UV irradiance: results of a campaign at the Salar de Uyuni. Bolivia, J. Photoch. Photobio. B, 87 , 1-8, 2007.

Rieder, H. E., Staehelin, J., Weihs, P., Vuilleumier, L., Maeder, J. A., Holawe, F., Blumthaler, M., Lindfors, A., Peter, T., Simic, S., Spichtinger, P., Wagner, J. E., Walker, D., and Ribatet, M.: Relationship between high daily erythemal UV doses, total ozone, surface albedo and cloudiness: an analysis of 30 years of data from Switzerland and Austria, Atmos. Res., 98, 9-20, 2010.

Schmucki, D. A. and Philipona, R.: Ultraviolet radiation in the Alps: the altitude effect, Opt. Eng., 41, 3090-3095, 2002.

Seckmeyer, G., Mayer, B., Bernhard, G., Erb, R., Albold, A., Jager, H., and Stockwell, W. R.: New maximum UV irradiance levels observed in Central Europe, Atmos. Environ., 31, 2971-2976, 1997.

Siani, A. M., Casale, G. R., Diémoz, H., Agnesod, G., Kimlin, M. G., Lang, C. A., and Colosimo, A.: Personal UV exposure in high albedo alpine sites, Atmos. Chem. Phys., 8, 3749-3760, doi:10.5194/acp-8-3749-2008, 2008.

Seckmeyer, G., Mayer, B., Bernhard, G., Erb, R., Albold, A., Jager, H., Stockwell, W. R.: New maximum UV irradiance levels observed in Central Europe, Atmos. Environ., 31, 2971-2976, 1997.

Simic, S., Fitzka, M., Schmalwieser, A., Weihs, P., and Hadzimustafic, J.: Factors affecting UV irradiance at selected wavelengths at Hoher Sonnblick, Atmos. Res., 101, 869-878, 2011.
Smolskaia, I., Masserot, D., Lenoble, J., Brogniez, C., and de la Casinière, A.: Retrieval of the ultraviolet effective snow albedo during 1998 winter campaign in the French Alps, Appl. Optics, 42, 1583-1587, 2003.

Sola, Y., Lorente, J., Campmany, E., de Cabo, X., Bech, J., Redano, A., Martínez-Lozano, J. A., Utrillas, M. P., Alados-Arboledas, L., Olmo, F. J., Díaz, J. P., Expósito, F. J., Cachorro, V., Sorribas, M., Labajo, A., Vilaplana, J. M., Silva, A. M., and Badosa, J.: Altitude effect in UV radiation during the Evaluation of the Effects of Elevation and Aerosols on the Ultraviolet Radiation 2002 (VELETA-2002) field campaign, J. Geophys. Res., 113, D23202, doi:10.1029/2007JD009742, 2008.

Van der Leun, J. C., Tang, X., and Tevini, M.: Environmental Effects of Ozone Depletion, 1998 Assessment, J. Photoch. Photobio. B, 46, 1-108, 1998.

Vanicek, K., Frei, T., Litynska, Z., and Shmalwieser, A.: UV-Index for the Public, COST-713 Action, Brussels, 27 pp., 2000.

Vernez, D., Milon, A., Vuilleumier, L., Bulliard, J.-L., Koechlin, A., Boniol, M., and Dore, J. F.: A general model to predict individual exposure to solar UV by using ambient irradiance data, J. Expo. Sci. Env. Epid., 25, 113-118, doi:10.1038/jes.2014.6, 2014.

Wagner, J. E., Angelini, F., Blumthaler, M., Fitzka, M., Gobbi, G P., Kift, R., Kreuter, A., Rieder, H. E., Simic, S., Webb, A., and Weihs, P.: Investigation of the 3-D actinic flux field in mountainous terrain, Atmos. Res., 102, 300-310, 2011.

WMO, WCRP: A preliminary cloudless standard atmosphere for radiation computations, WCP-112, WMO/TD-24, World Clim Res. Programme, Int. Assoc. for Meteorol. and Atmos. Phys., Geneva, 53 pp., 1987.

Zaratti, F., Forno, R. N., Fuentes, J. G., and Andrade, M. F.: Erythemally weighted UV variations at two high-altitude locations, J. Geophys. Res., 108, 4263, doi:10.1029/2001JD000918 2003. 